\title{
Fabrication of Carbon Nanotube-Reinforced 6061Al Alloy Matrix Composites by an In Situ Synthesis Method Combined with Hot Extrusion Technique
}

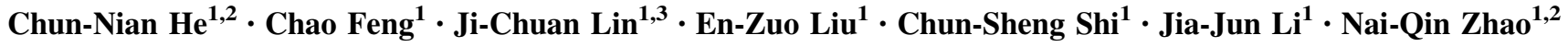

Received: 14 October 2015/Revised: 1 January 2016/Published online: 8 February 2016

(c) The Chinese Society for Metals and Springer-Verlag Berlin Heidelberg 2016

\begin{abstract}
Carbon nanotube (CNT)-reinforced 6061Al alloy matrix composites were prepared by chemical vapor deposition (CVD) combined with hot extrusion technique. During the preparation process, the 6061 Al flakes obtained by ball milling of the $6061 \mathrm{Al}$ spherical powders were subjected to surface modification to introduce a hydrophilic polyvinyl alcohol (PVA) membrane on their surface (6061Al@PVA) to bond strongly with nickel acetate [Ni(II)]. Then the 6061Al@PVA flakes bonded with Ni(II) were calcined and reduced to Ni nanoparticles, which were then heat-treated at $580{ }^{\circ} \mathrm{C}$ to remove PVA for obtaining even $\mathrm{Ni} / 6061 \mathrm{Al}$ catalyst. After that, the as-obtained $\mathrm{Ni} / 6061 \mathrm{Al}$ catalyst was employed to synthesize CNTs on the surface of the 6061Al flakes by CVD. After hot extrusion of the CNT/6061Al composite powders, the as-obtained CNT/6061 Al bulk composites with $2.26 \mathrm{wt} \%$ CNTs exhibited $135 \%$ increase in yield strength and $84.5 \%$ increase in tensile strength compared to pristine $6061 \mathrm{Al}$ matrix.
\end{abstract}

KEY WORDS: Metal matrix composites (MMCs); Microstructure; Mechanical properties; Carbon

\section{Introduction}

Since their landmark paper by Iijima [1], carbon nanotubes (CNTs) have attracted much attention during the past decade due to their unique physical and chemical properties [2]. A particular interest is the use of CNTs in the reinforcement of composites as a means of overcoming the

Available online at http://link.springer.com/journal/40195

Chun-Nian He

cnhe08@tju.edu.cn

Nai-Qin Zhao

nqzhao@tju.edu.cn

1 School of Materials Science and Engineering, Tianjin Key Laboratory of Composite and Functional Materials,

Tianjin University, Tianjin 300072, China

2 Collaborative Innovation Center of Chemical Science and Engineering, Tianjin 300072, China

3 Chengdu SIWI High-Tech Industry Co. Ltd, Chengdu 611731, China performance limits of conventional materials, owing to the remarkable mechanical properties as well as high aspect ratio and light weight of CNTs [3]. Although the main research efforts over the past decade have been focused on CNT-reinforced polymer and ceramic matrix composites [4-7], recently, more and more attention has been paid to the CNT-reinforced metal matrix composites (MMCs) after the first article appeared in 1998 on CNT/Al composites [8]. It is well known that the key and the most difficult issue for fabricating CNT-reinforced MMCs with high performance consists in the homogeneous dispersion of the CNTs into the metal matrix. This is mainly attributable to the strong agglomeration of CNTs in the powder form, as very strong van der Waals force exists that leads to mutual attraction rather than homogenous dispersion. Many methods have been developed to incorporate the CNTs into metal powders for preparing CNT-reinforced MMCs [931], and among these, the common methods are the mechanical mixing methods including high-energy ball milling [9, 12, 15, 16, 20-22], friction stir processing [23], and plasma spraying [26]. However, structural damage to 
CNTs is inevitably induced by mechanical impaction during mechanical mixing ball milling and plasma spraying, which are very unfavorable for strengthening the composites [14]. Therefore, it is necessary to develop a fabrication process for CNT-reinforced MMCs with a homogeneous dispersion of CNTs and a reduction of the damage to CNTs.

Recently, we have developed an in situ chemical vapor deposition (CVD) approach to disperse the CNTs into the metal powders to fabricate CNT-reinforced MMCs with good reinforcement efficiency [32]. In the present work, we employed a modified in situ CVD synthesis method combined with hot extrusion technique to produce uniform CNT-reinforced Al alloy (6061Al) matrix composites. In this modified synthesis strategy, firstly, the 6061Al flakes obtained by ball milling of the 6061 Al spherical powders were chosen as the matrix due to their large surface area [33], which is very favorable for increasing the amount of homogeneously dispersed CNTs on the 6061Al surface. Secondly, polyvinyl alcohol (PVA), a highly hydrophilic polymer, was used to modify the surface of 6061Al flakes, to make their surface properties more compatible with the catalyst precursor [nickel acetate, Ni(II)] [34]. Thirdly, through forming complex compounds with PVA, the catalyst precursor, Ni(II), can be evenly anchored to the PVA on the surface of 6061Al flakes, which can influence the following uniform growth of CNTs on the 6061Al flakes during the CVD process. Compared with the mechanical ball milling and plasma-spraying methods, the in situ synthesis approach is beneficial for controlling the homogeneous dispersion and perfect structural maintenance of CNTs in the 6061Al matrix. Moreover, the CVD-grown CNTs coated with a thin amorphous carbon layer can react with $6061 \mathrm{Al}$ to form a thin $\mathrm{Al}_{4} \mathrm{C}_{3}$ transition layer at the interface between the matrix and the CNT reinforcement, which would improve the interfacial bonding between the CNTs and the 6061Al matrix. As a consequence, the CNTstrengthened 6061 Al matrix composite produced by in situ CVD followed by hot extrusion process exhibits an excellent mechanical performance.

\section{Experimental}

The fabrication procedures of the CNT/6061Al powders are illustrated in Fig. 1. Firstly, the 6061Al spherical powders ( $\sim 20 \mu \mathrm{m}$ in diameter, $99 \%$ purity) were placed in a stainless steel mixing jar containing 40 stainless steel grinding balls of $6 \mathrm{~mm}$ diameter, which gave the ball to powder ratio of 15:1. The jar, filled with Ar gas, was then agitated using a ball mill at $500 \mathrm{r} / \mathrm{min}$. Four batches of 6061 Al powders were ball-milled for 5, 15, 30, 45, 60, 90, and 120 min. During the ball mixing, pure ethanol $(99.7 \%$ purity) was added as the processing control agent.

The 6061Al flake powders obtained by ball milling for 60 min were stirred in a $3.0 \mathrm{wt} \%$ PVA (molecular weight about 77,000) hydrosol for $60 \mathrm{~min}$, filtered and rinsed with distilled water to obtain PVA-modified 6061Al (indicated with6061Al@PVA) flakes. After that, the 6061Al@PVA flakes were stirred in a nickel acetate solution $(0.1 \mathrm{~mol} / \mathrm{L})$ for $0.5 \mathrm{~h}$ and filtered. The as-prepared powders were calcined at $250{ }^{\circ} \mathrm{C}$ for $60 \mathrm{~min}$ under $\mathrm{Ar}$ and reduced in hydrogen atmosphere at $450{ }^{\circ} \mathrm{C}$ for $60 \mathrm{~min}$. In order to eliminate PVA, the powders were heat-treated in flowing Ar at $580{ }^{\circ} \mathrm{C}$ for $60 \mathrm{~min}$, and $\mathrm{Ni} / 6061 \mathrm{Al}$ catalyst was obtained. Finally, the Ni/6061Al catalyst was subjected to CVD at $600{ }^{\circ} \mathrm{C}$ for a certain time (5-45 min) in a mixture flow of $\mathrm{CH}_{4} / \mathrm{Ar}(100 / 400 \mathrm{~mL} / \mathrm{min}, 99.99 \% / 99.99 \%$ purity) to grow CNTs with various contents. After the growth of CNTs, the furnace was cooled down to room temperature under $\mathrm{Ar}$, and $\mathrm{CNT} / 6061 \mathrm{Al}$ composite powders were obtained. The content of CNTs $\left(C_{\mathrm{CNTs}}\right)$ in the composite powders was calculated according to the following equation:

$C_{\mathrm{CNTs}}=\frac{A-B}{B} \times 100 \%$,

where $A$ is the weight of the CNT/6061Al composite powders obtained by $\mathrm{CVD}$ and $B$ is the weight of the $\mathrm{Ni}$ / 6061Al catalyst.

Hot extrusion was employed to consolidate the CNT/ 6061Al composite powders and pristine 6061 Al powders. Prior to hot extrusion, they were compacted to a column with a diameter of $10 \mathrm{~mm}$ under a pressure of $600 \mathrm{MPa}$, which was then sintered in flowing Ar atmosphere at $630{ }^{\circ} \mathrm{C}$ for $1 \mathrm{~h}$. Ultimately, hot extrusion was conducted at $500{ }^{\circ} \mathrm{C}$ with an extrusion ratio of $16: 1$ to obtain the CNT/ 6061Al bulk composites. The corresponding samples of pristine $6061 \mathrm{Al}$ without CNTs were also prepared under the same procedures for comparison.

Scanning electron microscopy (SEM) was conducted by field-emission SEM (FESEM, JSM-6700F). Transmission electron microscopy (TEM) and high-resolution TEM (HRTEM) were performed on a FEI Tecnai $G^{2}$ F20. X-ray diffraction (XRD) measurements were taken on a Rigaku $\mathrm{D} / \mathrm{max}$ diffractometer with $\mathrm{Cu} K_{\alpha}$ radiation at a wavelength of $1.5406 \AA$, and a step size of $0.02^{\circ}$. Raman spectrum was recorded on the LabRAM HR Raman spectrometer using laser excitation at $514.5 \mathrm{~nm}$ from an argon ion laser source to evaluate the structure of the CNTs. Fourier transform infrared spectroscopy (FTIR) on a Spectrum 100 (PerkinElmer Inc., USA) was used to characterize the 6061A1@PVA and 6061Al@PVA after annealing. The density of the composites was measured by the Archimedes method. To determine the mechanical properties, hardness 


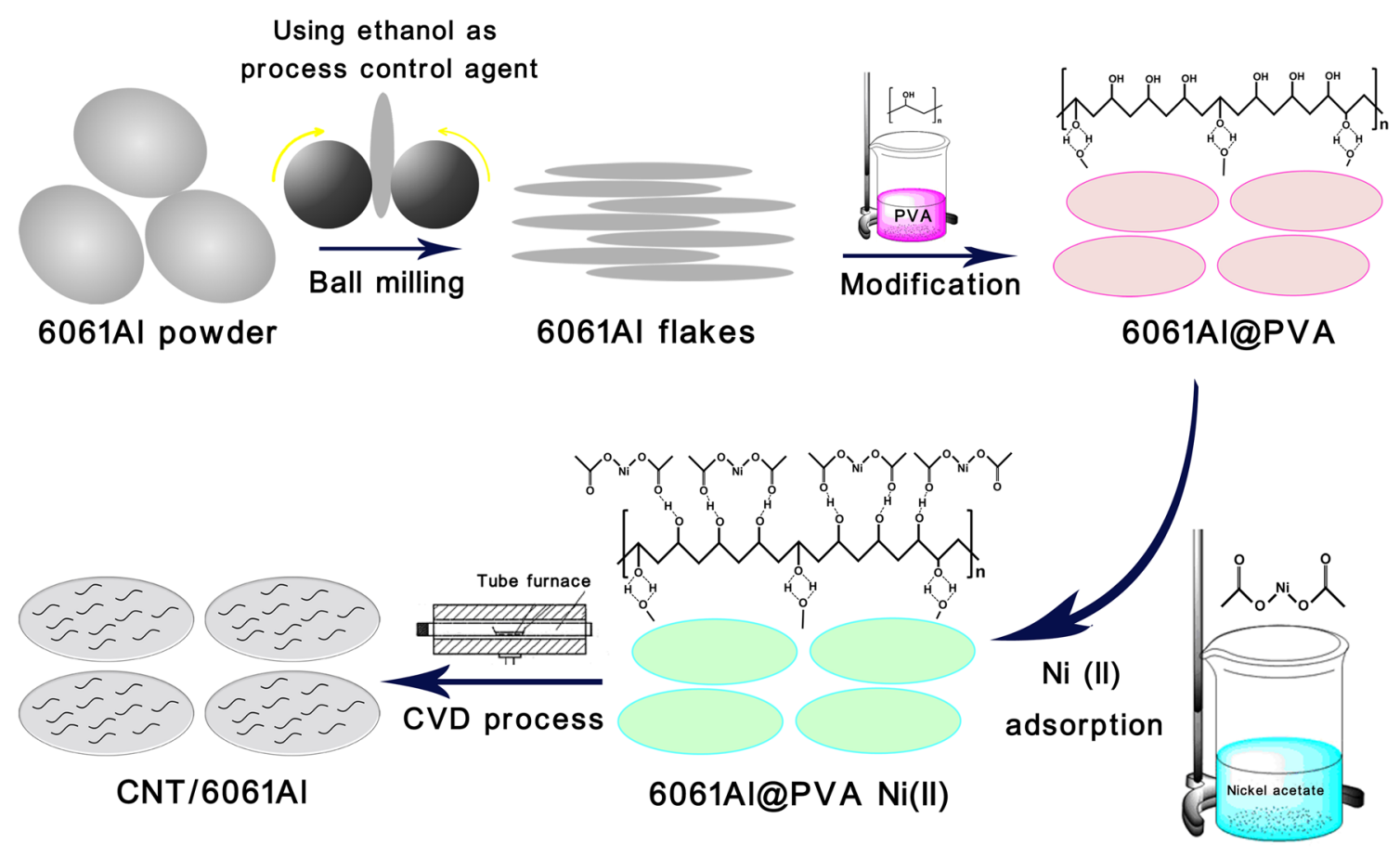

Fig. 1 Production processes of CNT/6061Al composite powders

of the composites was measured using a LECO LM247AT micro-hardness tester after appropriate polishing procedure. For tensile testing, the dog-bone samples with gauge length of $20 \mathrm{~mm}$ and gauge diameter of $4 \mathrm{~mm}$ were machined.

\section{Results and Discussion}

\subsection{Effect of Ball Milling Time on the Morphology of the 6061Al Flakes}

It is reported that during mechanical ball milling, plastic deformation, cold-welding, and fracture are the predominant factors, in which the deformation leads to a change in particle shape, cold-welding leads to an increase in particle size, and fracture leads to a decrease in particle size [35]. Figure 2 shows the morphology evolution of the 6061Al particles with increase in the milling time from 0 to 90 min, and Table 1 exhibits the effect of ball milling time on the diameter and thickness of the 6061Al flakes. From Fig. 2a, it can be seen that the original 6061Al particles have an irregular spherical shape with a relatively narrower size distribution $(\sim 20 \mu \mathrm{m}$ in diameter). After $5 \mathrm{~min}$ of milling, the majority of the 6061Al particles exhibit irregular spherical shape with a larger size than that of the raw 6061Al particles, and some of them become flake shaped, as shown in Fig. 2b, indicating that at this stage, the deformation mechanism is the predominant process. After $15 \mathrm{~min}$ of milling, 6061Al is in the shape of flakes composed of a few welded layers and their average diameter and thickness are about 16 and $11 \mu \mathrm{m}$, respectively. These flakes will tend to weld together until bigger and thinner flakes form, as shown in Fig. 2c for the 6061Al after $45 \mathrm{~min}$ of milling. With the increase in ball milling time, the 6061 Al flakes continue to become thinner, larger,
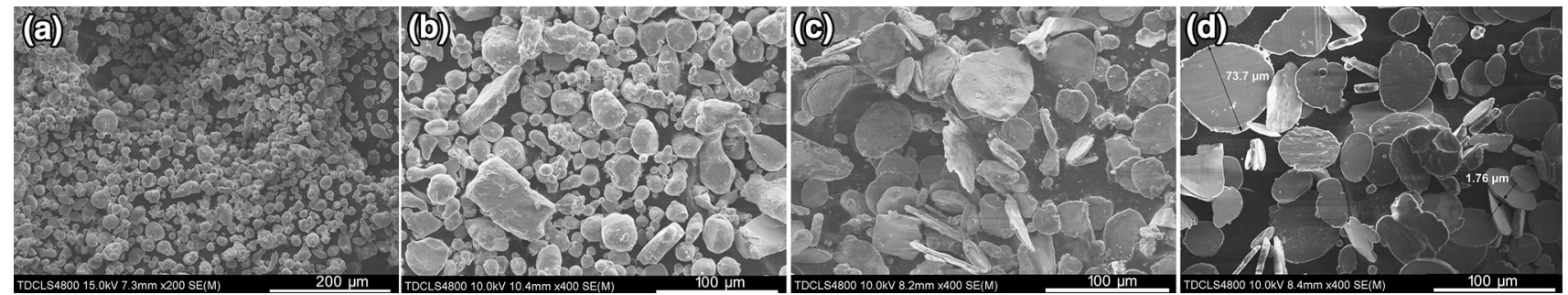

Fig. 2 SEM micrographs showing the effects of milling time on 6061Al morphology: a initial; b 5 min; c 45 min; d 60 min 
Table 1 Effect of milling time on the morphology of the 6061 Al particles

\begin{tabular}{lllcl}
\hline Milling time $(\mathrm{min})$ & Morphology & Average diameter of flakes $(\mu \mathrm{m})$ & Average thickness of flakes $(\mu \mathrm{m})$ & Specific surface area $\left(\mathrm{m}^{2} / \mathrm{g}\right)$ \\
\hline 5 & Uneven particles & - & - & - \\
15 & Flakes & 16 & 11 & 0.01 \\
30 & Flakes & 20 & 6 & 0.04 \\
45 & Flakes & 44 & 3 & 0.08 \\
60 & Flakes & 55 & 2 & 0.13 \\
90 & Flakes & 56 & 2 & 0.13 \\
120 & Flakes & 57 & 2 & 0.15 \\
\hline
\end{tabular}

and smoother. After 60 min of milling, the flakes with a very smooth surface show an average diameter of about $55 \mu \mathrm{m}$ and an average thickness of about $2 \mu \mathrm{m}$, as shown in Figs. 2d and 3. Further increasing the ball milling time beyond $60 \mathrm{~min}$ does not cause a distinct change in flake diameter and thickness, implying that a state of equilibrium between fracturing and cold-welding is reached.

Based on relationship among the ball milling time, the diameter and thickness of the flakes, we have calculated the specific surface area of the flakes as a function of milling time, with the results shown in Table 1 . As it can be seen, once spherical powders with a diameter of $20 \mu \mathrm{m}$ are ballmilled into flakes with a thickness of about $2 \mu \mathrm{m}$, their specific surface area increases to about five times larger than that of the powders without ball milling. The large surface area would be very helpful for the dispersion of active catalysts and CNTs on the flakes. In this case, a higher content of CNTs homogeneously grown on 6061Al flakes can be more easily achieved by an in situ CVD method. Furthermore, the content of CNTs in the CNT/ 6061 Al composite powders can be controlled by varying the content of catalyst, the growth time and the $6061 \mathrm{Al}$

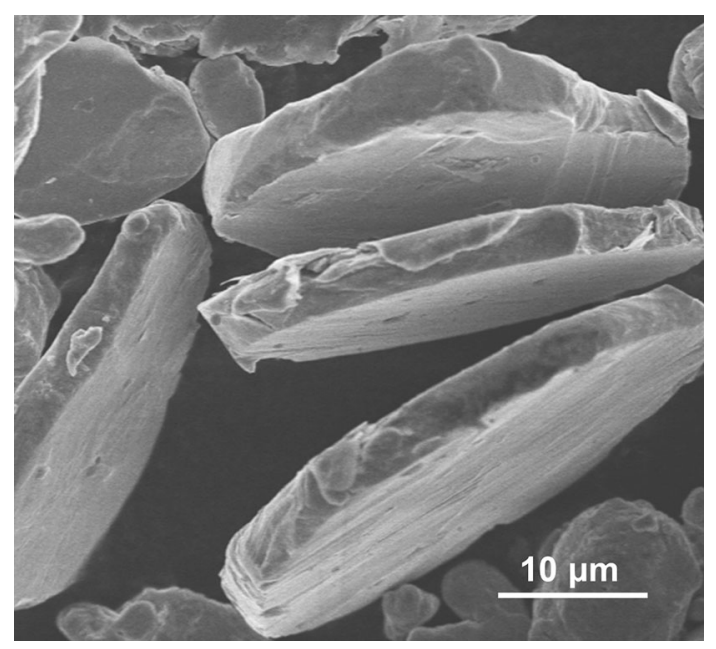

Fig. 3 SEM images of the 6061 Al flakes obtained by ball milling for $60 \mathrm{~min}$ flake thickness. In general, more CNTs can be grown on 6061Al flakes when increasing the content of catalyst and the synthesis time of CNTs. In addition, decreasing the flake thickness is an effective way to increase the loading capacity of CNTs, because the surface area of flakes with a thickness of $1 \mu \mathrm{m}$ is five times that for a thickness of $5 \mu \mathrm{m}$, which means five times the CNT loading capacity for the 6061Al flakes. As a result, with the same content of CNTs being synthesized by a fixed time and catalyst content, the thinner the 6061Al flakes are, the fewer CNTs there are on a certain specific surface area, which would lead to a better uniformity of CNTs in CNT/6061 Al composite powders. In the present work, the 6061Al flakes with a thickness of about $2 \mu \mathrm{m}$ obtained by ball milling for $60 \mathrm{~min}$ were employed as the matrix due to their relatively large surface area and appropriate size for CNT growth.

\subsection{Characterization of $\mathrm{Ni} / 6061 \mathrm{Al}$ Catalyst}

In our previous work [32], we have found that uniform dispersion of Ni nanoparticles on the surface of $\mathrm{Al}$ powders had great influence on the homogeneous growth of CNTs in the CNT/Al composite powders. In order to obtain uniform Ni/6061Al catalyst, we have employed PVA to modify the surface of the 6061Al flakes to increase their wettability because PVA is a water-soluble polymer and is widely used as a binder, surfactant, corrosion inhibitor, and processing control agent in the field of metal powder processing and water-borne coatings and/or pigments [34]. The as-obtained 6061Al@PVA flakes with quite a number of $-\mathrm{OH}$ group can connect to $\mathrm{Ni}$ (II) with carboxyl groups $(-\mathrm{COOH})$ by hydrogen bonding, and in this case $\mathrm{Ni}$ (II) can be uniformly anchored on the 6061Al flake surface. Once the stable complex between Ni(II) and PVA form, Ni(II) is tightly locked in the PVA film on the surface of 6061Al flakes, making it unable to migrate during the subsequent processing such as filtering and drying. As a result, the desorption and agglomeration of the $\mathrm{Ni}$ (II) can be avoided and thus the 6061Al flakes with homogeneously adsorbed $\mathrm{Ni}$ (II) are achieved, which is very favorable for the subsequent even synthesis of CNTs on the 6061Al flakes. 
Figure 4a shows the results of the FTIR measurement, and the successful coating of PVA film on the surface of 6061 Al flakes can be verified by the above curve. The peaks at 2920 and $2853 \mathrm{~cm}^{-1}$ are due to the asymmetric and symmetric $\mathrm{C}-\mathrm{H}$ stretching vibration. The absorption at $3000-3500 \mathrm{~cm}^{-1}$ shows a wide peak, and this is assigned to the $\mathrm{O}-\mathrm{H}$ stretching vibrations. The sharp peak appeared at $1728 \mathrm{~cm}^{-1}$ is due to ester functional group of unhydrolyzed polyvinyl acetate repeat unit. The transmittance bands at $926 \mathrm{~cm}^{-1}$, indicating the $\mathrm{C}-\mathrm{OH}$ stretching of PVA, a characteristic of PVA, confirms the successful modification of PVA on the 6061Al flakes [33, 34]. Though the PVA is beneficial for promoting the link between 6061Al flakes and $\mathrm{Ni}(\mathrm{II})$, its existence would be detrimental to the growth of CNTs and the final mechanical properties of the composites. Therefore, the $\mathrm{Ni} /$ 6061Al@PVA flakes were heat-treated at $580{ }^{\circ} \mathrm{C}$ for 60 min to eliminate PVA and obtain pure Ni/6061 Al catalyst. In order to confirm that the PVA has been removed during the pyrolysis process, the Ni/6061Al@PVA flakes after pyrolysis were also characterized by using FTIR spectra. As can be seen in the curve below of Fig. 4a, the characteristic peaks of PVA almost disappeared, indicating that the PVA could be totally eliminated during the pyrolysis process $[33,34]$.

Figure $4 \mathrm{~b}$ shows the XRD pattern of the $\mathrm{Ni} / 6061 \mathrm{Al}$ catalyst. It can be seen that only $\mathrm{Al}$ and $\mathrm{Ni}$ peaks exist in the catalyst, indicating that the $\mathrm{Ni}(\mathrm{II})$ has been completely converted to $\mathrm{Ni}$ after reduction. The distribution of $\mathrm{Ni}$ catalyst on the 6061Al flakes is shown in Fig. 4c, d. According to Fig. $4 \mathrm{c}$, it can be observed that the Ni particles with nanometer size are evenly distributed on the surface of $6061 \mathrm{Al}$ flakes, and almost no agglomeration of $\mathrm{Ni}$ particles is found. This uniform distribution of $\mathrm{Ni}$ nanoparticles is mainly attributed to the steric effect of PVA, which plays an important role in preventing the $\mathrm{Ni}$ (II) from migration during the filtering and drying processes and thus prevents the $\mathrm{Ni}$ nanoparticles from agglomeration and growing bigger. A more detailed observation of the $\mathrm{Ni} / 6061 \mathrm{Al}$ catalyst is conducted by TEM, as seen in Fig. 4d. It is suggested that the welldispersed $\mathrm{Ni}$ nanoparticles, as indicated with arrows, should have good interfacial bond with 6061Al matrix, which is verified by the fact that the Ni catalytic particles
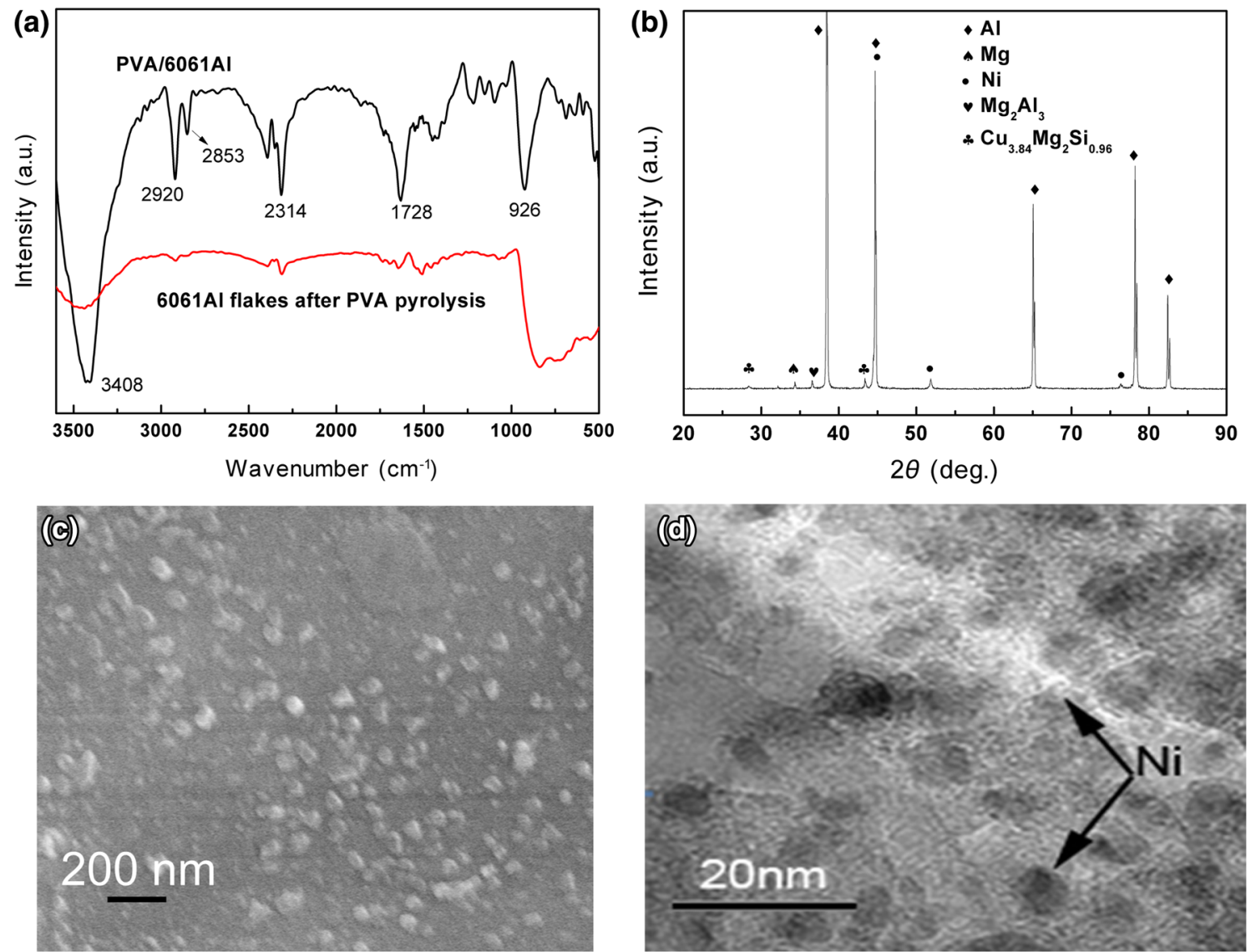

Fig. 4 a FTIR spectra of PVA-modified 6061Al flakes and the 6061Al flakes after PVA pyrolysis; b XRD pattern of Ni/6061Al catalyst; c SEM image of $\mathrm{Ni} / 6061 \mathrm{Al}$ catalyst; $\mathbf{d} \mathrm{TEM}$ image of $\mathrm{Ni} / 6061 \mathrm{Al}$ catalyst 
still adhere to the $6061 \mathrm{Al}$ flakes after sonicating in ethanol for $30 \mathrm{~min}$ during the preparation of TEM sample. Moreover, the size of the quasi-sphere $\mathrm{Ni}$ nanoparticles ranges between 5 and $20 \mathrm{~nm}$, which is beneficial for producing CNTs with a narrow distribution of diameters.

\subsection{Characterization of CNT/6061Al Composite Powders}

The morphology of as-synthesized CNT/6061Al composite powders after CVD process was investigated by SEM and TEM. As can be seen in Fig. 5a, b, when the reaction time of CVD was fixed to $40 \mathrm{~min}$, the surface of 6061Al flakes is decorated with relatively homogeneously grown CNTs, which is attributed to the uniform distribution of the $\mathrm{Ni}$ nanoparticles, and the weight fraction of CNTs in composite powders was calculated to be $2.26 \mathrm{wt} \%$. According to Fig. 5b, we can see that the CNTs have the diameters from 8 to $25 \mathrm{~nm}$ and the length about $1 \mu \mathrm{m}$, which results in a large aspect ratio for CNTs to act as reinforcement fiber in composites. The as-grown CNTs were further investigated by TEM, as shown in Fig. 5c. It is demonstrated that the crooked CNTs are well graphitized and multi-walled, having a tubular structure. The graphitic sheets of the CNTs that parallel to the direction of the axis are apparent, and the interlayer spacing between the sheets is $0.34 \mathrm{~nm}$, consistent with the ideal graphitic interlayer space $(0.34 \mathrm{~nm})$. In particular, it should be noted that many of the CVD-grown CNTs are coated with a thin amorphous carbon layer (Fig. 5c), which should be very reactive with 6061 Al at high temperatures [36, 37]. Apart from this, it was found that almost each CNT has a nanoparticle encapsulated in one of its end, as indicated with arrows in Fig. 5b. These nanoparticles were supposed to be $\mathrm{Ni}$ that acted as the catalyst for the CNT growth.

The as-obtained CNT/6061Al composite powders fabricated by CVD for 40 min were also characterized by Raman spectroscopy in detail to further validate the relatively high graphitization degree of the CNTs in the composite powders. Representative Raman spectrum obtained for the CNT/ 6061 Al composite powders is shown in Fig. 5d. The spectrum was collected within the $800-2000 \mathrm{~cm}^{-1}$ range, corresponding to the spectral region that provides the most valuable data on the structure of carbon materials [38, 39]. The recorded spectrum shows two broad Raman bands at around 1342.7 and $1606.9 \mathrm{~cm}^{-1}$. The latter band corresponds to the $E_{2 \mathrm{~g}}$ mode (stretching vibrations) in the basal plane of the crystalline graphite ( $G$ graphitic peak). The width of the $G$-band is related to the extent of disorder within the carbon $s p^{2}$ plane graphene layer. The band located at $1342.7 \mathrm{~cm}^{-1}$ ( $D$-band) is associated with disorder, being allowed by zone edge modes of the graphite structure that becomes active due to the lack of long-range order in amorphous and quasi-crystalline forms of carbon materials $[38,39]$. The intensity ratio of the $D$-band to the $G$-band (corresponding to the vibrations) $\left(I_{D} / I_{G}\right)$ was calculated to be 0.82 . The low relative intensity of the $D$-band peak implies that the as-grown CNTs are mainly composed of well-crystallized graphite, which is in agreement with the HRTEM observations.

In order to investigate the effect of growth time of CNTs on the morphology of the CNT/6061Al composite powders, we have employed SEM to characterize the distribution of CNTs on the surface of the 6061Al flakes. Figure 6 presents the surface morphologies of the $2 \mu \mathrm{m}$ thick 6061Al flakes loaded with various weight fractions of the CNTs prepared by CVD for various time. As it can be seen, a mass of nanowires are attached to the surface of the 6061Al flakes, and almost no CNT clusters are evident even when the weight fraction of CNTs reaches as high as 1.05 and $2.26 \mathrm{wt} \%$, as shown in Figs. 6a, b and 5a, b, respectively. However, when the growth time increases to $45 \mathrm{~min}$, the 6061 Al flakes are coated with dense CNTs, and several clusters can be found in the SEM images of Fig. 6c, d.

For comparison, we have also investigated the surface morphologies of $20 \mu \mathrm{m}$ spherical 6061Al powders loaded with the $2.26 \mathrm{wt} \% \mathrm{CNTs}$, which were obtained by CVD for $40 \mathrm{~min}$, the results are shown in Fig. 6e, f. As can be seen, a mass of dense and entangled CNTs have covered the surface of spherical $6061 \mathrm{Al}$ powders and the uniformity of CNTs is much worse than that for the 2- $\mu$ m-thick $6061 \mathrm{Al}$ flakes (see Fig. 5a, b). As mentioned above, when the $20-\mu \mathrm{m}$ spherical 6061Al powders were ball-milled into
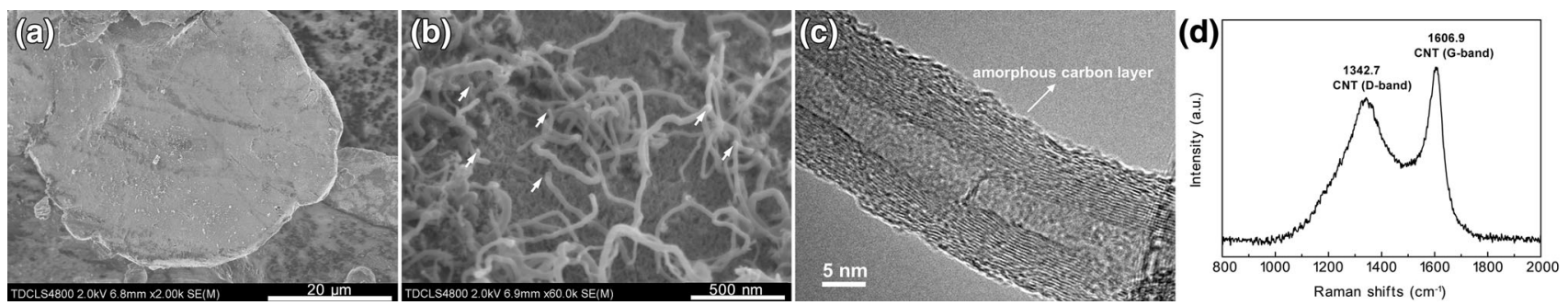

Fig. 5 SEM images a, b, TEM image c, Raman spectrum d of the CNT/6061Al composite powders fabricated by CVD for $40 \mathrm{~min}$ 

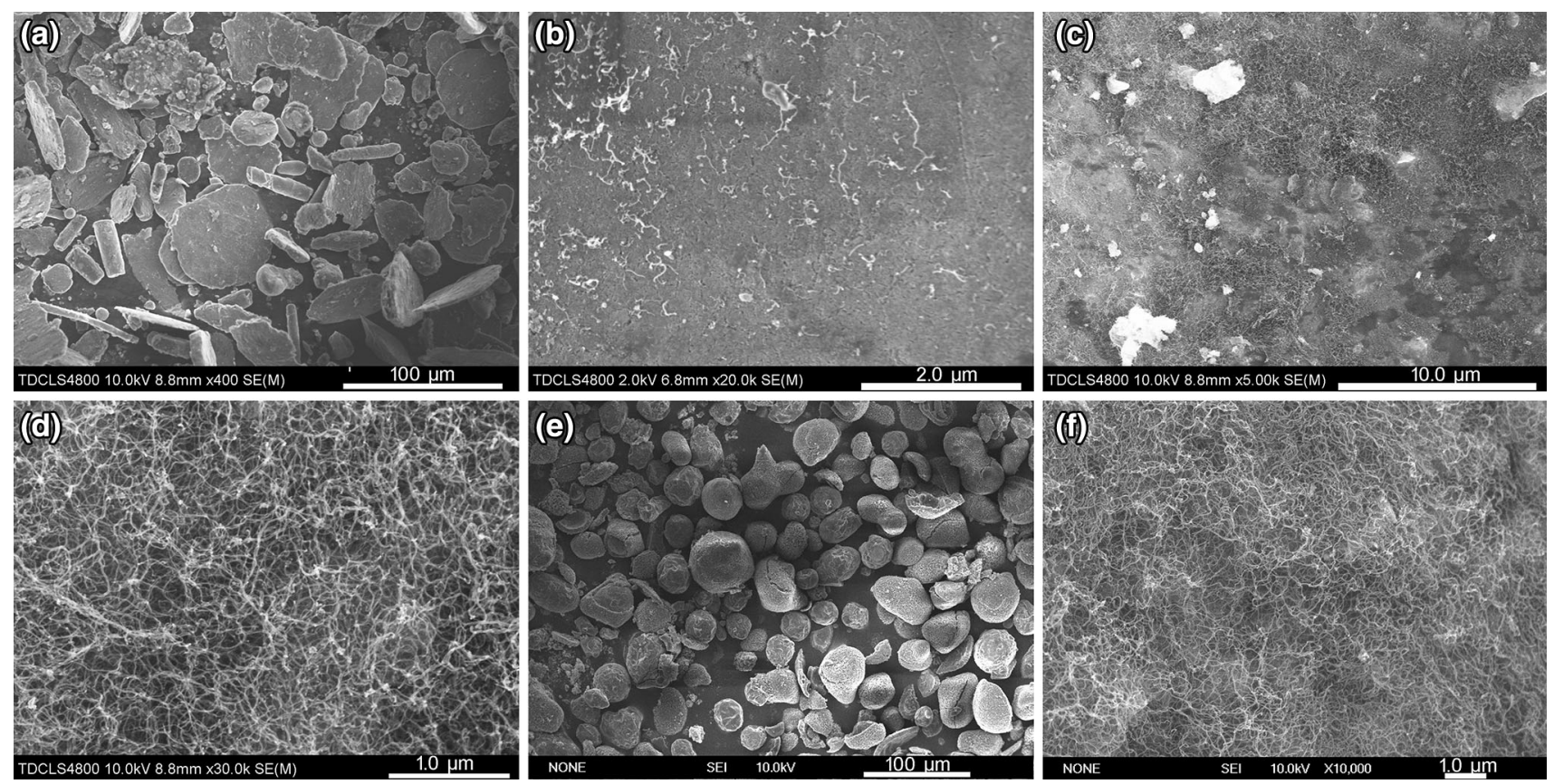

Fig. 6 SEM images of the CNT/6061Al fabricated by CVD for various time: a, b flake powders, 20 min, 1.05 wt $\%$ CNTs; $\mathbf{c}$, d flake powders, $45 \mathrm{~min}, 3.01 \mathrm{wt} \%$ CNTs; e, f spherical powders, $40 \mathrm{~min}$

2- $\mu$ m-thick 6061Al flakes, the specific surface area increased by five times, and this means four times higher than the CNT loading capacity for the $2-\mu \mathrm{m}$-thick $6061 \mathrm{Al}$ flakes. Moreover, the thin $6061 \mathrm{Al}$ flakes can provide a mass of flat surfaces to accommodate the adequate loading of the longer CNTs, as shown in Fig. 6a-d. Therefore, the high surface area and flat morphology of flake powders play an important role in achieving the high loading capacity and uniform distribution of CNTs during the in situ CVD process.

\subsection{Physical and Mechanical Properties of CNT/6061Al Composites}

After having controlled the in situ synthesis of the CNTs on the $6061 \mathrm{Al}$ flakes, bulk materials were produced by hot extrusion of the in situ synthesized CNT/6061 Al composite powders and some of their physical and mechanical properties were measured. These results are reported in Fig. 7 and Table 2 for different composite compositions. The pristine 6061 Al bulk and the CNT/6061Al bulk composites prepared by ball milling followed by hot extrusion process were also produced under the same conditions for comparison.

Figure 7a displays the density of the composites as a function of the weight fraction of CNT reinforcement. The density almost linearly decreases with increasing amount of CNTs from about $2.70 \mathrm{~g} / \mathrm{cm}^{3}$ for pristine $6061 \mathrm{Al}$ bulk to $2.45 \mathrm{~g} / \mathrm{cm}^{3}$ for the composite with $3.01 \mathrm{wt} \%$ CNTs. This leads to a reduction in density of about $3 \%$ for each weight percent of CNT added. Moreover, it also can be seen that the CNT/6061Al composites with the CNT contents ranging from 0.76 to $2.26 \mathrm{wt} \%$ have a relative density of more than $96 \%$, exhibiting relatively fully densifying behavior after the hot extrusion process. This result indicates that the hot extrusion process employed in this study is a suitable process for fully densifying the in situ synthesized CNT/6061Al composite powders with a relatively low CNT content. However, when the CNT content is increased to $3.01 \mathrm{wt} \%$, the densifying effect of the composite becomes worse, which may be due to the agglomeration of CNTs in the composites, as shown in Fig. 6e, $\mathrm{f}$.

The micro-hardness test results are shown in Fig. $7 \mathrm{~b}$ and Table 2 . The $6061 \mathrm{Al}$ shows relatively higher hardness when the samples are reinforced with 0.76-2.26 wt\% CNTs. Moreover, it can be observed that with increase in the CNT content from 0 to $2.26 \mathrm{wt} \%$, the hardness of the composites is increased from 77.5 to $100.0 \mathrm{HV}$. This could be due to the refinement of the $6061 \mathrm{Al}$ matrix grain size and the effective load transition from the matrix to the CNTs during the deformation, reflecting the high interfacial strength and the homogeneous dispersion of the CNTs within the matrix $[20,32]$. However, when the CNT content increases as high as $3.01 \mathrm{wt} \%$, the hardness of the CNT/6061Al composites is only $69.5 \mathrm{HV}$, which is even lower than the pristine $6061 \mathrm{Al}$ material. This may be attributed to the agglomeration of CNTs that resulted in poor bonding in the composites and thus the lower hardness for the composites. 

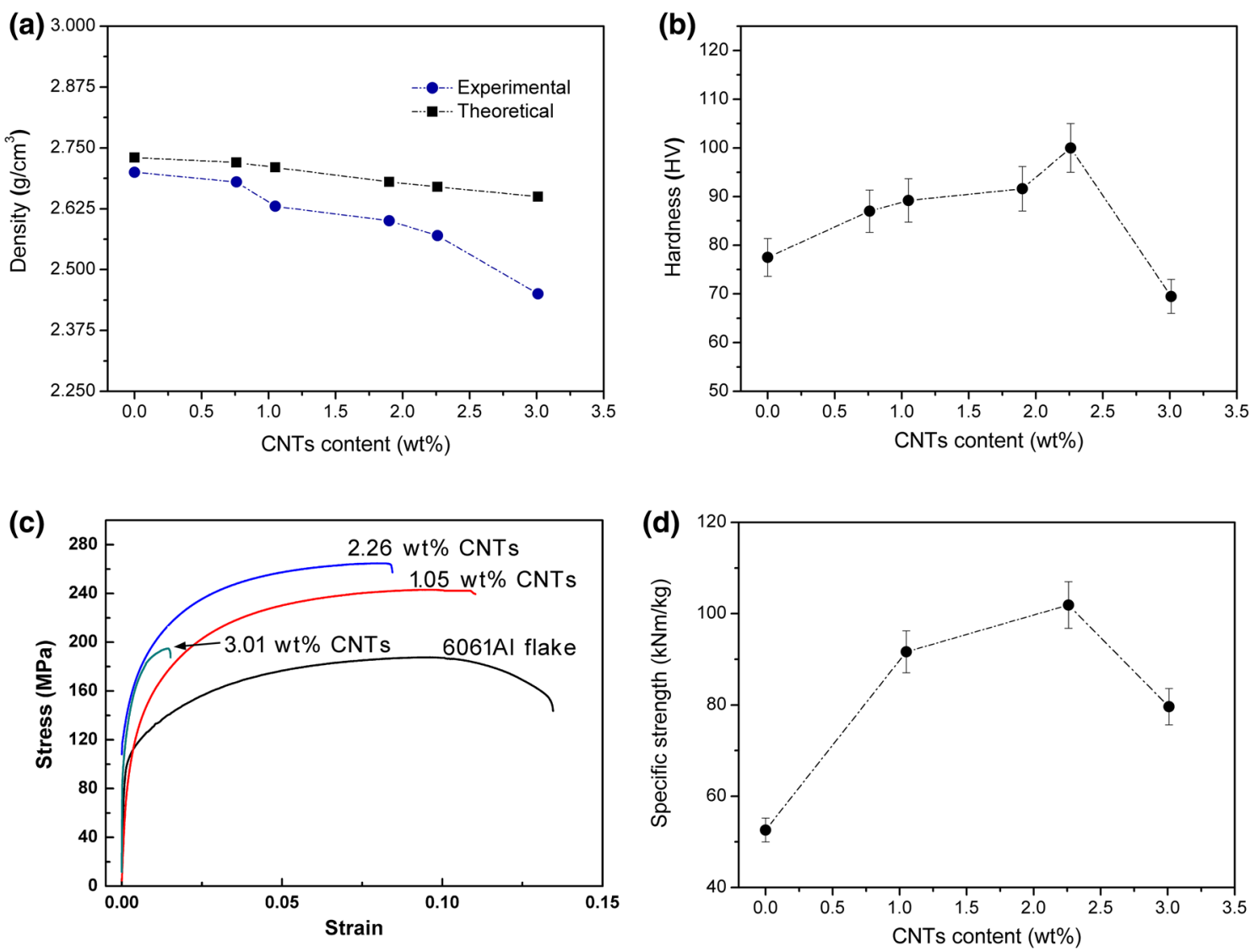

Fig. 7 Density $\mathbf{a}$ and hardness $\mathbf{b}$ of the composites as a function of CNTs contents; $\mathbf{c}$ room-temperature true stress-strain curves in tensile test for the pristine $6061 \mathrm{Al}$ and $\mathrm{CNT} / 6061 \mathrm{Al}$ composites with CNTs contents in the range of 0 to $3.01 \mathrm{wt} \%$; $\mathbf{d}$ specific strength of the composites as a function of CNTs contents

Table 2 Properties of the extruded 6061Al, CNTs/6061Al composites produced by in situ CVD and CNTs/6061Al composites produced by mechanical ball milling process

\begin{tabular}{|c|c|c|c|c|c|c|}
\hline Sample & $\begin{array}{l}\text { Theoretical } \\
\text { density }\left(\mathrm{g} / \mathrm{cm}^{3}\right)\end{array}$ & $\begin{array}{l}\text { Relative } \\
\text { density (\%) }\end{array}$ & $\begin{array}{l}\text { Yield strength } \\
\text { (MPa) }\end{array}$ & $\begin{array}{l}\text { Ultimate tensile } \\
\text { strength (MPa) }\end{array}$ & $\begin{array}{l}\text { Elongation } \\
(\%)\end{array}$ & $\begin{array}{l}\text { Hardness } \\
(\mathrm{HV})\end{array}$ \\
\hline Pristine $6061 \mathrm{Al}$ & 2.73 & 98.9 & 77 & 142 & 13.7 & 77.5 \\
\hline 6061Al-0.76 wt $\%$ CNTs & 2.72 & 98.5 & - & - & - & 87.0 \\
\hline $6061 \mathrm{Al}-1.05 \mathrm{wt} \% \mathrm{CNTs}$ & 2.71 & 97.0 & 162 & 241 & 11.2 & 89.2 \\
\hline $6061 \mathrm{Al}-1.9 \mathrm{wt} \% \mathrm{CNTs}$ & 2.68 & 97.0 & - & - & - & 91.6 \\
\hline $6061 \mathrm{Al}-2.26$ wt $\%$ CNTs & 2.67 & 96.3 & 181 & 262 & 8.5 & 100.0 \\
\hline 6061Al-3.01 wt\% CNTs & 2.65 & 92.5 & 120 & 195 & 1.8 & 69.5 \\
\hline $6061 \mathrm{Al}-2.26 \mathrm{wt} \% \mathrm{CNTs}^{\mathrm{a}}$ & 2.67 & 94.5 & 111 & 199 & 5.6 & 82 \\
\hline
\end{tabular}

a Composite which was fabricated by mechanical ball milling

Typical room-temperature tensile true stress-true strain curves for the composites are shown in Fig. $4 \mathrm{c}$ together with the curve for the extruded pristine $6061 \mathrm{Al}$ bulk. As can be seen, the addition of the CNT reinforcement is very effective for improving the mechanical properties of the $6061 \mathrm{Al}$ matrix. In particular, the composites with 1.05 and $2.26 \mathrm{wt} \%$ of CNTs display a remarkable deformation behavior. The specimen with $1.05 \mathrm{wt} \%$ exhibits a yield strength of about $162 \mathrm{MPa}$. After yielding the stress increases with increasing strain, and the sample exhibits a pronounced work hardening up to $241 \mathrm{MPa}$, reaching an ultimate strain of $11.2 \%$ before fracture occurs. With increase in the weight fraction of CNTs to $2.26 \mathrm{wt} \%$, both the yield and the tensile strength further raise to about 181 
and $262 \mathrm{MPa}$, respectively, and the strain at break is about $8.5 \%$. These results indicate that the addition of the CNT reinforcement leads to composite materials with yield and tensile strengths exceeding that of pristine $6061 \mathrm{Al}$ by a factor of 1.5 to 2, while retaining appreciable plastic deformation. However, the tensile strength of the material is only about $195 \mathrm{MPa}$ for the samples with $3.01 \mathrm{wt} \%$ of CNTs; meanwhile, the composites show a remarkably reduced plastic deformation of about $1.8 \%$. To further verify the strengthening effect of the in situ synthesized CNTs for the composites, we have also compared the mechanical properties of in situ synthesized 6061 Al$2.26 \mathrm{wt} \%$ CNT composite with the 6061Al-2.26 wt\% CNT composite prepared by mechanical ball milling process. As can be seen in Table 2, the hardness and tensile strength of the in situ synthesized CNT/6061 Al composite are 1.22 and 1.32 times, respectively, that of the composites with a similar composition fabricated by a traditional mechanical ball milling method, indicating the superiority of in situ synthesis method.

A high specific strength (tensile or compressive strength divided by the density) is one of the most important aspects of lightweight materials. In the current composites containing high weight fractions of reinforcement, the CNTs lead to a remarkable strengthening contribution to the mechanical properties of the $6061 \mathrm{Al}$ matrix. Moreover, the addition of low-density CNTs decreases the density of the composites below that of pristine $6061 \mathrm{Al}$ (as shown in Table 2). The increase in strength together with the simultaneous decrease in density remarkably increases the specific strength of the current composites, as shown in Fig. 7d. The specific strength sharply increases from about $52 \mathrm{kNm} / \mathrm{kg}$ for pristine $6061 \mathrm{Al}$ to $92 \mathrm{kNm} / \mathrm{kg}$ for the composite with $1.05 \mathrm{wt} \%$ of CNTs. The specific strength further increases with increasing weight fraction of reinforcement up to about $102 \mathrm{kNm} / \mathrm{kg}$ for the composite with $2.26 \mathrm{wt} \%$. These values of specific strength are higher than those reported for $\mathrm{TiB}_{2 \mathrm{p}} / 6061 \mathrm{Al}$ [40] and $\mathrm{Al}_{18} \mathrm{~B}_{4} \mathrm{O}_{33} /$ 6061 Al [41] composites evaluated by tensile tests of the composites without any heat treatment, which indicates that composites reinforced with CNTs may be a valid alternative to conventional ceramic-reinforced composites.

\subsection{Strengthening Mechanism of the CNT/6061Al Composites}

In order to illustrate the strengthening mechanism of the $\mathrm{CNT} / 6061 \mathrm{Al}$ composites, the fracture surface and interfacial microstructure of the $\mathrm{CNT} / 6061 \mathrm{Al}$ composite with $2.26 \mathrm{wt} \%$ CNT were investigated by SEM and TEM, respectively. Figure 8 shows the fracture surface of the composites. As can be seen from Fig. 8a, the composites exhibit a general fracture surface characteristic of ductile materials with lots of deep dimples, which indicates that the interfaces between the 6061Al particles are very strongly metal-metal bonded. However, some dimples are not significantly deep as in the ordinary fracture surface of pristine $6061 \mathrm{Al}$, which is why the composites exhibit relatively less elongation (approximately 8.5\%) than that of pure 6061 $\mathrm{Al}$ (approximately 13.7\%), as shown in Fig. 7c. In addition, it can be observed that the CNTs are dispersed very well into the $6061 \mathrm{Al}$ matrix, most CNTs are broken and very few CNTs were pulled out. Moreover, the length of pull-out CNTs is about $100 \mathrm{~nm}$, much lower than the average length of $1 \mu \mathrm{m}$ for the original CNTs. It is reported that a weak interface between the CNTs and metal matrix leads to interfacial debonding and pull-out of the CNTs from the matrix, whereas a strong interface results in a broken CNT [14, 17, 32]. A stress transfer to a CNT is affected by the shear strength at the CNT/matrix interface in the CNT/6061 $\mathrm{Al}$ composite. When the maximum shear stress reaches the interfacial shear strength, debonding at the CNT/matrix interface occurs, and the CNT is pulled out. Above results indicate that there is a very strong interfacial bonding in the $6061 \mathrm{Al}-2.26 \mathrm{wt} \% \mathrm{CNT}$ composite where the embedded CNTs are very difficult to pull out from the 6061 Al matrix, which is very beneficial for the effective transfer of the stress from the matrix to the CNTs and the improvement on the mechanical properties of the composite.

Figure 9 shows the TEM and HRTEM images of interfacial microstructure of the 6061Al-2.26 wt\% CNT composites. As can be seen, CNTs in the composites present a perfect structure of apparent graphene layers, indicating that almost no structural damage to the CNTs occurs after hot extrusion process. Moreover, the composite exhibits a good interfacial bonding between the CNTs and $6061 \mathrm{Al}$ matrix, and there is a thin transition layer (about 1-5 $\mathrm{nm}$ ) between them. The typical diffraction pattern (Fig. 9c) shows several rings and some diffraction spots, suggesting that the interfacial layer is crystalline and has a polycrystalline structure. The indexation of the rings shows the presence of aluminum carbide $\left(\mathrm{Al}_{4} \mathrm{C}_{3}\right)$, which has a rhombohedral structure of space group $R-3 \mathrm{~m}$ and has unit cell parameters of $a=0.334 \mathrm{~nm}$ and $c=2.50 \mathrm{~nm}$. The presence of uniform $\mathrm{Al}_{4} \mathrm{C}_{3}$ transition layer at the interface of $6061 \mathrm{Al}$ and CNTs is particularly important to interface bonding properties.

Research indicated that the contact angle of $\mathrm{Al}$ on carbon changes from about $135^{\circ}-140^{\circ}$ to $50^{\circ}-70^{\circ}$ when a reaction layer of $\mathrm{Al}_{4} \mathrm{C}_{3}$ is formed [42]. In addition, several works have reported the interfacial reaction between CNTs and $\mathrm{Al}$ or $\mathrm{Al}$ alloy. For example, $\mathrm{Ci}$ et al. [37] have found that the interfacial reaction between the $\mathrm{Al}$ and CVDgrown CNT layers generally occurred at locations containing an amorphous carbon coating, at defect sites, and at 

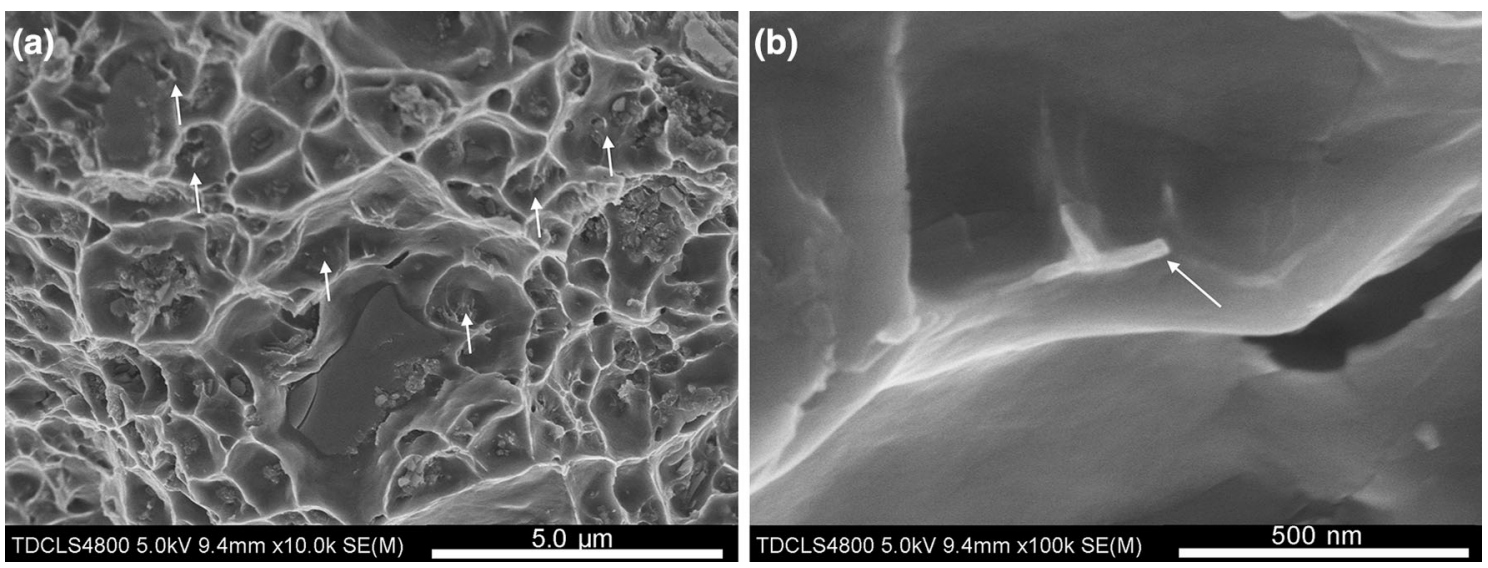

Fig. 8 SEM fractographs of the hot extruded 6061Al-2.26 wt\% CNTs composite: a low magnification SEM image of the general fracture surface; b high magnification SEM image of a typical pull-out CNT
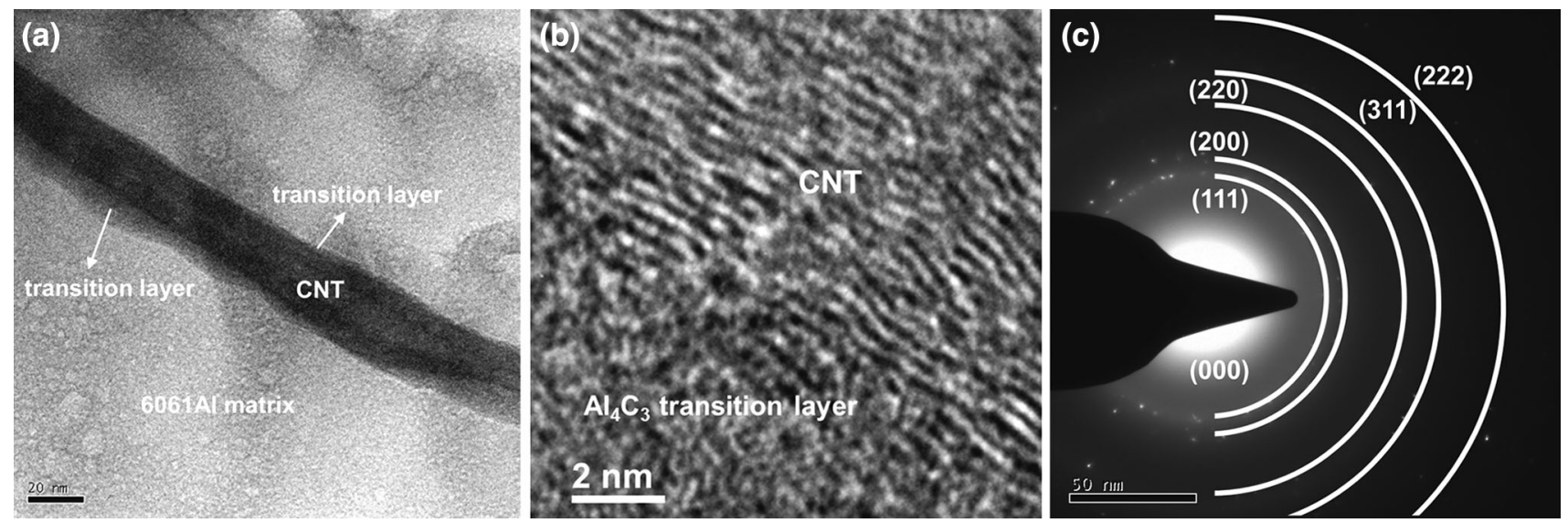

Fig. 9 a, b TEM images of interfacial microstructure of the 6061Al-2.26 wt\% CNT composite; c selected-area diffraction pattern of the interfacial transition layer

open ends of CNTs. The $\mathrm{Al}_{4} \mathrm{C}_{3}$ formed on the surface as well as on the tips of the CNTs improves the interfacial interaction between the CNTs and the Al layers, contributing to the enhancement of the mechanical properties of the composite. Kwon et al. [29] also found that the $\mathrm{Al}_{4} \mathrm{C}_{3}$ helps in load transfer by pinning the CNTs to the matrix, and the extent and nature of chemical reactions can be changed by either by controlling the chemistry of the matrix or by using coatings on reinforcements. It is well known that $\mathrm{Al}_{4} \mathrm{C}_{3}$ prefers to form and grow along the reactive prism planes of carbon due to the higher surface free energy at the graphitic prism planes than the basal planes [14, 37, 42]. Generally, CVD-grown CNTs have some defects along their outer walls, which means that some graphitic prism planes can contact with the metal matrix. In addition, CVD-grown CNTs have an amorphous carbon coating on their surface. These defects together with the amorphous carbon will lead to easy formation of $\mathrm{Al}_{4} \mathrm{C}_{3}$ $[14,37,42]$. Therefore, the $6061 \mathrm{Al}$ matrix and the CVD- grown CNT reinforcement in our composite were able to link together, chemically bonded through the formation of $\mathrm{Al}_{4} \mathrm{C}_{3}$, resulting in the load being efficiently transferred from the $6061 \mathrm{Al}$ matrix to the CNT reinforcement $[36,37]$. From this point of view, the thin amorphous carbon coating on in situ CVD-grown CNTs is ideal for metal matrix composite applications.

The results presented above show that: (1) A lot of broken CNTs as well as few pulled-out CNTs are evenly distributed on the fracture surface of the composites (Fig. 5a); (2) The surfaces are typical of ductile fractures and that the cylindric shape and length of CNT are conserved despite the aggressive hot extrusion process they were subjected to; and (3) A thin $\mathrm{Al}_{4} \mathrm{C}_{3}$ transition layer was formed at the interface between the CNTs and the 6061Al matrix. According to these evidences, the increase in the strength can be associated with the following mechanisms: the dispersion strengthening of the homogeneously dispersed CNTs with perfect structure, load transfer at the CNT/metal interface, 
and/or CNT dislocation interactions according to the Orowan bowing mechanism [43]. Particularly, it should be mentioned that the formation of $\mathrm{Al}_{4} \mathrm{C}_{3}$ interfacial layer greatly improves the interfacial bonding between the CNTs and the matrix, which is especially important to improve the composite performance, because it can cause high load translation during tensile processes, as suggested by pulling out and broken of CNTs in Fig. 5a and thus raise the fracture energy and the tensile strength of the composites [36, 37]. However, as for the CNT/6061Al composite produced by mechanical ball milling process, the graphitization structure of CNTs would be badly destroyed $[8,14,23]$. As a result, the wall of the CNTs will react with $6061 \mathrm{Al}$ and thus severely degrade the reinforcement effect of the CNTs on the composites (as shown in Table 2).

\section{Conclusion}

CNT/6061 Al composites, fabricated by a combination of the in situ CVD method and the hot extrusion process, exhibit much improved yield strength, ultimate tensile strength, and hardness, which are originated from the homogeneously dispersed CNTs in the 6061 Al matrix and the strong interfacial bonding between the CNTs and the matrix. For example, the as-obtained CNT/6061Al composite with $2.26 \mathrm{wt} \%$ CNTs presents a $135 \%$ increase in yield strength and $84.5 \%$ increase in tensile strength compared to pristine $6061 \mathrm{Al}$ matrix. The strengthening mechanism of the CNT/ $6061 \mathrm{Al}$ composites was thought to be associated with the dispersion strengthening of the CNTs with perfect structure, load transfer at the CNT/metal interface, and/or CNT dislocation interactions according to the Orowan bowing mechanism. Particularly, the formation of thin $\mathrm{Al}_{4} \mathrm{C}_{3}$ greatly improves the interfacial bonding between the CNTs and the matrix, which thus remarkably raises the fracture energy and the tensile strength of the composites.

Acknowledgments This work was financially supported by the High Technology Research and Development Program of China (No. 2013AA031002), National Natural Science Funds for Excellent Young Scholar (No. 51422104), and the National Natural Science Foundation of China (Nos. 51531004, 51272173 and 51472177).

\section{References}

[1] S. Iijima, Nature 354, 56 (1991)

[2] M.M.J. Treacy, T.W. Ebbesen, J.M. Gibson, Nature 381, 678 (1996)

[3] J.P. Salvetat-Delmotte, A. Rubio, Carbon 40, 1729 (2002)

[4] R. Mangu, S. Rajaputra, V.P. Singh, Nanotechnology 22, $215502(2011)$

[5] Y. Gogotsi, Science 330, 1332 (2012)

[6] K.E. Thomson, D. Jiang, W. Yao, R.O. Ritchie, A.K. Mukherjee, Acta Mater. 60, 622 (2012)
[7] G.D. Zhan, J.D. Kunts, J. Wan, A.K. Mukherjee, Nat. Mater. 2, 28 (2003)

[8] T. Kuzumaki, K. Miyazawa, H. Ichinose, K. Ito, J. Mater. Res. 13, 2445 (1998)

[9] Z.Q. Tan, Z.Q. Li, G.L. Fan, W.H. Li, Q.L. Liu, W. Zhang, D. Zhang, Nanotechnology 22, 225603 (2011)

[10] S. Cho, K. Kikuchi, A. Kawasaki, Acta Mater. 60, 726 (2012)

[11] I. Firkowska, A. Boden, A.M. Vogt, S. Reich, J. Mater. Chem. 21, 17541 (2011)

[12] P. Jenei, J. Gubicza, E.Y. Yoon, H.S. Kim, J.L. Lábár, Compos Part A 51, 71 (2013)

[13] C. Guiderdoni, C. Estournès, A. Peigney, A. Weibel, V. Turq, C. Laurent, Carbon 49, 4535 (2011)

[14] S.R. Bakshi, D. Lahiri, A. Agarwal, Int. Mater. Rev. 55, 41 (2010)

[15] E.C. Vermisoglou, E. Devlin, T. Giannakopoulou, G. Romanos, N. Boukos, V. Psycharis, C. Lei, C. Lekakou, D. Petridis, C. Trapalis, J. Alloys Compd. 590, 102 (2014)

[16] Z.J. Li, B.C. Yang, G.Q. Yun, S.R. Zhang, M. Zhang, M.X. Zhao, J. Alloys Compd. 550, 353 (2013)

[17] S.I. Cha, K.T. Kim, S.N. Arshad, C.B. Mo, S.H. Hong, Adv. Mater. 17, 1377 (2008)

[18] K.T. Kim, S.I. Cha, T. Gemming, J. Eckert, S.H. Hong, Small 4, $1936(2008)$

[19] J.Y. Hwang, B.K. Lim, J. Tiley, R. Banerjee, S.H. Hong, Carbon 57, 287 (2013)

[20] L. Jiang, Z. Li, G. Fan, L. Cao, D. Zhang, Scr. Mater. 66, 331 (2012)

[21] H. Kwon, S. Cho, M. Leparoux, A. Kawasaki, Nanotechnology 23, 225704 (2012)

[22] K. Hansang, L. Marc, Nanotechnology 23, 415701 (2012)

[23] Z.Y. Liu, B.L. Xiao, W.G. Wang, Z.Y. Ma, Carbon 62, 35 (2013)

[24] W.J. Kim, S.H. Lee, Compos. Part A 67, 308 (2014)

[25] W.J. Kim, Y.J. Yu, Scr. Mater. 72-73, 25 (2014)

[26] T. Laha, Y. Chen, D. Lahiri, A. Agarwal, Compos. A 40, 589 (2009)

[27] I.N. Mazov, I.A. Ilinykh, V.L. Kuznetsov, A.A. Stepashkin, K.S. Ergin, D.S. Muratov, V.V. Tcherdyntsev, D.V. Kuznetsov, J.P. Issi, J. Alloys Compd. 586, S440 (2014)

[28] L. Wang, H. Choi, J.M. Myoung, W. Lee, Carbon 47, 3427 (2009)

[29] H.S. Kwon, M. Estili, K. Takagi, T. Miyazaki, A. Kawasaki, Carbon 47, 570 (2009)

[30] S.H. Dong, J.Q. Zhou, D. Hui, Y. Wang, S. Zhang, Compos. A 68, 356 (2015)

[31] J. Tang, G.L. Fan, Z.Q. Li, X.D. Li, R. Xu, Y. Li, D. Zhang, W.J. Moon, S.D. Kaloshkin, M. Churyukanova, Carbon 55, 202 (2013)

[32] C.N. He, N.Q. Zhao, C.S. Shi, X.W. Du, J.J. Li, H.P. Li, Q.R. Cui, Adv. Mater. 19, 1128 (2007)

[33] L.L. Cao, Z.Q. Li, G.L. Fan, L. Jiang, D. Zhang, W.J. Moon, Y.S. Kim, Carbon 50, 1057 (2012)

[34] J.Y. Gong, S.H. Yu, H.S. Qian, L.B. Luo, T.W. Li, J. Phys. Chem. C 111, 2490 (2007)

[35] A. Esawi, K. Morsi, Compos. A 38, 646 (2007)

[36] T. Laha, S. Kuchibhatla, S. Seal, W. Li, A. Agarwal, Acta Mater. 55, 1059 (2007)

[37] L.J. Ci, Z.Y. Ryu, N.Y. Jin-Phillip, M. Ruhle, Acta Mater. 54, 5367 (2006)

[38] Y.L. Hsin, K.C. Hwang, C.T. Yeh, J. Am. Chem. Soc. 129, 9999 (2007)

[39] C.N. He, S. Wu, N.Q. Zhao, C.S. Shi, E.Z. Liu, J.J. Li, ACS Nano 7, 4459 (2013)

[40] L.T. Jiang, G.Q. Chen, X.D. He, M. Zhao, Z.Y. Xiu, R.J. Fan, Trans. Nonferrous Met. Soc. China 19, s542 (2009)

[41] H.Q. Gao, L.D. Wang, W.D. Fei, Mater. Sci. Eng. A 479, 261 (2008)

[42] K. Landry, S. Kalogeropoulou, N. Eustathopoulos, Mater. Sci. Eng. A 254, 99 (1998)

[43] R. George, K.T. Kashyap, R. Rahul, S. Yamdagni, Scr. Mater. 53, 1159 (2005) 